\title{
ADIÇÃO DE ÁGUA EM RAÇÕES PARA SUÍNOS EM TERMINAÇÃO
}

\author{
LEONARDO ATTA FARIAS ${ }^{1}$, ROMÃo dA CUNHA NUNES ${ }^{2}$, JOSÉ HENRIQUE STRINGHINI ${ }^{2}$, JULIANA LUIS E \\ SILVA $^{3}$, ALESSANDRA GIMENEZ MASCARENHAS ${ }^{2}$, TAYRONE FREITAS PRADO ${ }^{3}$ \\ ${ }^{1}$ Professor Doutor da Universidade Federal do Piauí, Bom Jesus, PI, Brasil - leonardoatta@ yahoo.com.br. \\ ${ }^{2}$ Professores Doutores da Universidade Federal de Goiás, Goiânia, GO, Brasil. \\ ${ }^{3}$ Pós-graduandos da Universidade Federal de Goiás, Goiânia, GO, Brasil.
}

\begin{abstract}
Para avaliar a adição de água em rações fareladas na digestibilidade de nutrientes e de energia, o desempenho, a qualidade dos dejetos e as características de carcaça, para suínos em terminação, foram utilizados 12 suínos machos, castrados, híbridos comerciais, com peso inicial de $64,0 \pm 4,8 \mathrm{~kg}$, em um ensaio metabólico, distribuídos em delineamento em blocos ao acaso, com base no peso inicial. Outros dezoito suínos machos, castrados, híbridos comerciais e dezoito fêmeas, híbridas comerciais, com peso inicial de $60,0 \pm 3,6 \mathrm{~kg}$, foram utilizados no ensaio de desempenho, distribuídos em delineamento inteiramente casualizado. Formulou-se uma ração para atender às exigências dos animais, a qual consistiu no tratamento seco. O segundo e terceiro tratamentos consistiram da mesma ração, com a adição de igual proporção e do dobro de água, respectivamente. Não
\end{abstract}

houve diferença estatística entre os tratamentos para os coeficientes de digestibilidade aparente da matéria seca, energia bruta, extrato etéreo, cálcio e fósforo, para as variáveis de desempenho, umidade, nitrogênio e fósforo fecal e características de carcaça. A redução da ingestão de água por animais que recebem dieta líquida foi de $27,97 \%$. A adição de água em rações de suínos na fase de terminação não influencia a digestibilidade aparente dos nutrientes da dieta nem o desempenho dos animais, quando o arraçoamento é realizado duas vezes ao dia. Além disso, não influencia na composição da carcaça, porém diminui a ingestão de água, levando a um menor desperdício quando os animais vão ao bebedouro e reduz a excreção de fósforo, podendo refletir, de forma positiva, no volume e no poder poluente dos dejetos.

PALAVRAS-CHAVE: Dejetos; desempenho; dieta líquida; suinocultura.

\section{WATER ADDITION TO RATIONS FOR PIGS IN FINISHING PHASE}

\section{ABSTRACT}

To evaluate the effects of water addition to mash rations on nutrients and energy digestibility, water intake, excrement quality and carcass traits in pigs at the finishing phase, twelve commercial hybrid barrows with an initial weight of $64.0 \pm 4.8 \mathrm{~kg}$ were used for the digestibility trial, and distributed into randomized blocks, based on the animals' weight. Eighteen barrows and eighteen hybrid females, with an initial weight of $60.0 \pm 3.6 \mathrm{~kg}$, were used for the performance test, and distributed into a completely randomized design. Treatment one consisted of a dry diet formulated to meet the animals' requirement. Treatments two and three consisted of the same diet with the addition of the same proportion of water and the double of water, respectively, the proportional unit used was $\mathrm{kg}$. There was no statistical difference among treatments for the coefficients of apparent dry matter digestibility, gross energy, ether extract, calcium and phosphorus, and for the variables of performance, moisture, fecal nitrogen and phosphorus and carcass characteristics. There was a reduction of $27.97 \%$ of fresh water intake for animals receiving liquid diet. The addition of water to the diet of pigs at finishing phase does not influence apparent nutrient digestibility, or animal performance when they are fed twice a day. Moreover, it does not influence carcass composition, but decreases fresh water intake, 
lessening the waste when the animals go to the drinker, and it reduces phosphorus excretion, reflecting positively on the volume and polluting power of the excrements.

KEYWORDS: Liquid feeding; performance; pig production; waste.

\section{INTRODUÇÃO}

O sistema de alimentação líquida é caracterizado pela diluição de ingredientes sólidos em componentes líquidos. O fornecimento das dietas líquidas pode ser realizado de diferentes formas, como pela adição de água (HAN et al., 2009; PEDERSEN \& STEIN, 2010; SILVA et al., 2011), pela incorporação de resíduos industriais líquidos fermentados (PLUMMED-FERRER \& WRIGHT, 2009; MISSOTTEN et al., 2010; PEDERSEN \& STEIN, 2010) ou não fermentados (CANIBE \& JENSEN, 2003) e pela inclusão de componentes acidificantes (DUNG et al., 2009).

Várias vantagens são atribuídas a esse sistema, entre eles a utilização de subprodutos da indústria alimentícia, efeitos positivos sobre a composição da microbiota gastrintestinal do animal, alternativa para elevação do consumo de ração em períodos quentes, melhora do desempenho, forma de diminuição do desperdício de ração pela redução do pó, além de maior conforto animal (BERTOL \& BRITO, 1995; JENSEN \& MIKKELSEN, 1998).

Destacam-se, também, como vantagens, a redução dos custos com a alimentação, a facilidade no arraçoamento duas ou três vezes ao dia e a possibilidade de fornecimento do alimento nos horários mais frescos do dia, principalmente em regiões quentes. Permite ainda a promoção de condições mais apropriadas para o uso de probióticos e/ou a ação das enzimas nas dietas e a possibilidade de diminuição da poluição ambiental causada pelos suínos, uma vez que esse sistema inclui a utilização mais adequada dos nutrientes pelos animais, incrementando a digestibilidade e reduzindo o volume de dejetos (BROOKS et al., 2003; PLUMMED-FERRER \& WRIGHT, 2009; MISSOTTEN et al., 2010).

BEAL et al. (2002) e FARZAN et al. (2006) relataram que a alimentação líquida pode estender suas vantagens também aos aspectos sanitários, especialmente auxiliando na redução dos riscos de contaminação microbiana para os animais. PLUMMED-FERRER \& WRIGHT (2009) afirmaram que as alterações de $\mathrm{pH}$ exercidas pelos alimentos liquidos, principalmente os fermentados, mostraram-se como uma forma complementar para controle de microrganismos.

Outro fator de importância sobre o fornecimento de dietas líquidas para suínos se refere à melhor qualidade da carcaça que os animais podem vir a produzir, o que está diretamente relacionado a condições de estresse; entretanto, pouco foi pesquisado sobre essa relação. Acredita-se que, ao fornecer dietas líquidas, pode ocorrer a melhoria da qualidade da carcaça, devido à redução da sensação de calor e pelo fato de a água estar associada ao mecanismo de termorregulação (SILVA et al, 2011; CANIBE \& JENSEN, 2012).

O emprego de alimentação líquida ainda depende de estudos para confirmar sua viabilidade. O conhecimento da adequada utilização dos nutrientes e tamanho da partícula dos ingredientes de uma ração umedecida com água poderá fornecer subsídios ao pesquisador sobre a digestibilidade dos nutrientes de uma dieta líquida (PEDERSEN \& STEIN, 2010). HAN et al. (2009) verificaram que dietas liquidas fornecidas por 10 dias para leitões com 30 dias de idade foram suficientes para incrementar a digestibilidade da matéria seca, da energia, da proteína bruta e da fração fibra em detergente neutro das dietas.

Este trabalho foi desenvolvido para avaliar os efeitos da adição de água em rações fareladas na digestibilidade de nutrientes e de energia, no desempenho, na ingestão de água, na qualidade dos dejetos e nas características de carcaça de suínos na fase de terminação.

\section{MATERIAL E MÉTODOS}

Foram realizados dois experimentos com suínos na fase de terminação, um de digestibilidade e outro de desempenho, desenvolvidos no Setor de Suinocultura e Laboratório de Nutrição Animal do Departamento de Produção Animal da Escola de Veterinária e Zootecnia da Universidade Federal de Goiás.

Para o ensaio metabólico, foram utilizados doze suínos machos, castrados, híbridos comerciais, com peso inicial de $64 \pm 4,8 \mathrm{~kg}$, distribuídos em delineamento em blocos ao acaso, com base no peso dos animais, com três tratamentos (níveis de água adicionados na ração) e quatro repetições, totalizando 12 unidades experimentais. Para o ensaio de desempenho, empregaram-se 18 suínos machos castrados e 18 fêmeas, todos híbridos comerciais, com peso inicial de $60 \pm 4,6 \mathrm{~kg}$, distribuídos em delineamento inteiramente casualizado, com os mesmos tratamentos, porém em seis repetições, 
totalizando 18 unidades experimentais.

As parcelas do ensaio de digestibilidade consistiram em um animal alojado por gaiola metabólica do tipo PEKAS (1968), posicionadas em galpão de alvenaria com cortinas e forro isotérmico. Já para o desempenho, as parcelas foram formadas por um animal macho e uma fêmea alojados em baia com piso compacto, dotada de comedouro de alvenaria e bebedouro do tipo chupeta.

Formulou-se uma ração para atender às exigências dos animais, conforme a categoria e as tabelas brasileiras de exigencias nutricionais e composição de alimentos para aves e suinos (ROSTAGNO et al., 2005). Um dos tratamentos foi caracterizado por uma ração seca. Os outros dois tratamentos consistiram na ração seca, com adição de igual proporção de água (relação água:ração 1:1) e com a adição do dobro de água (relação água:ração $2: 1$ ), caracterizados por rações úmidas e líquidas, respectivamente. A unidade proporcional utilizada foi o quilograma. A composição centesimal, nutricional e a energia da ração estão apresentadas na Tabela 1.

Tabela 1 - Composição centesimal e conteúdo nutricional da ração

\begin{tabular}{lc}
\hline Ingrediente & $\begin{array}{c}\text { Composição } \\
\text { centesimal (\%) }\end{array}$ \\
\hline Milho & 79,98 \\
Farelo de soja & 17,42 \\
Suplemento mineral e vitamínico & 0,30 \\
L - lisina HCL 78\% & 0,11 \\
Calcário & 0,39 \\
Fosfato bicálcico & 1,09 \\
Sal comum & 0,35 \\
Óleo vegetal & 0,35 \\
Total Conteúdo nutricional calculado & 100,00 \\
& 3.250 \\
Energia metabolizável (kcal/kg) & 14,50 \\
Proteína bruta (\%) & 0,679 \\
Lisina digestível (\%) & 0,211 \\
Metionina digestível (\%) & 0,484 \\
Cálcio (\%) & 0,248 \\
Fósforo disponível (\%) & 0,160 \\
Sódio (\%) & \\
\hline
\end{tabular}

${ }^{1}$ Quantidades por quilograma do produto: Vitamina A, 840.000 UI; Vitamina D3, $180.000 \mathrm{UI}$; Vitamina E, $3.300 \mathrm{mg}$; Vitamina K3, 240,00 mg; Vitamina B1, $135 \mathrm{mg}$; Vitamina B2, $660 \mathrm{mg}$; Vitamina B6, $135 \mathrm{mg}$; Vitamina B12, $2.700 \mathrm{mcg}$; Niacina, 4.200 $\mathrm{mg}$; Ácido Fólico, $75 \mathrm{mg}$; Ácido Pantotênico, $2.100 \mathrm{mg}$; Manganês, $4.500 \mathrm{mg}$; Zinco, $24.000 \mathrm{mg}$; Ferro, $16.250 \mathrm{mg}$; Cobre, $2.394 \mathrm{mg}$; Iodo, $90 \mathrm{mg}$; Selênio, $90 \mathrm{mg}$; Antioxidante, 235,87 mg; Promotor de Crescimento, $30.316 \mathrm{mg}$; Monóxido de Manganês, $27.000 \mathrm{mg}$; Óxido de Zinco, $144.000 \mathrm{mg}$; Sulfato de Cobre, $14.400 \mathrm{mg}$; Sulfato De Ferro, $99.000 \mathrm{mg}$; Iodato de Cálcio, $540 \mathrm{mg}$; ${ }^{2}$ base na matéria seca.

Ci. Anim. Bras., Goiânia, v.14, n.1, p. 1-7, jan./mar. 2013
Nos galpões em que os dois ensaios foram realizados, instalaram-se termo-higrômetros de mínima e máxima, na altura dos animais, para aferição da temperatura e da umidade interna do galpão, uma vez ao dia, durante todo o período experimental.

A duração do ensaio metabólico foi de 15 dias, sendo oito destinados à adaptação dos animais às gaiolas e às dietas experimentais e sete destinados à coleta das fezes e de urina. Em todo o período experimental, realizou-se o arraçoamento duas vezes por dia, às 7:00 e às 17:00 horas. $\mathrm{O}$ fornecimento de ração durante o período de coleta de material foi definido nos oito dias iniciais do experimento e teve por base o peso metabólico individual de cada animal $\left(\mathrm{kg}^{0,75}\right)$. Adicionou-se água à ração para cada refeição, sempre respeitando a proporção proposta pelos tratamentos (ração seca, relação água:ração 1:1 e relação água:ração $2: 1)$, com posterior homogeneização e fornecimento aos animais. A água in natura foi fornecida à vontade imediatamente após o consumo do alimento; no entanto, houve controle para cálculo de consumo de água. Tanto as quantidades de ração como a de água fornecidas foram sistematicamente registradas em fichas de controle individual.

Procedeu-se à coleta total das fezes diariamente e as amostras foram pesadas, ensacadas, registradas e armazenadas, em sacos plásticos identificados, sob congelamento. Coletou-se a urina diariamente em recipientes plásticos com $20 \mathrm{~mL}$ de $\mathrm{HCl}$ (1:1) adicionados, para evitar a perda de nitrogênio e a proliferação bacteriana. Em seguida, foram pesadas, registradas e homogeneizadas, sendo retirada uma porção de $200 \mathrm{~mL}$ para armazenamento sob congelamento.

Após o período de coleta, as fezes foram descongeladas e homogeneizadas para retirada de uma porção de $20 \%$ para pré-secagem a $55^{\circ} \mathrm{C}$, em estufa de ventilação forçada, durante 72 horas. Procedeu-se ao descongelamento da urina, bem como sua homogeneização, filtragem e acondicionamento sob refrigeração. Realizaram-se análises laboratoriais de cálcio e fósforo da ração e das fezes, bem como da matéria seca, do nitrogênio, da proteína e da energia da ração, fezes e urina segundo metodologia descrita por SILVA \& QUEIROZ (2002).

As quantidades de alimento fornecido, fezes e urina excretados, além dos valores das análises laboratoriais, foram utilizados nos cálculos de digestibilidade e metabolizabilidade descritos por SAKOMURA \& ROSTAGNO (2007), de acordo com as seguintes fórmulas: $\mathrm{CDA}=(\mathrm{NI}-\mathrm{NF}) / \mathrm{NI} \times 100$; onde: CDA é o 
coeficiente de digestibilidade aparente, NI é o nutriente ingerido e NF é o nutriente fecal; e $\mathrm{CMA}=(\mathrm{NI}-\mathrm{NF}-\mathrm{NU}) / \mathrm{MSI}$ x 100; em que: CMA é o coeficiente da energia metabolizável aparente, NI é a energia bruta ingerida, NF é energia bruta excretada pelas fezes, NU é a energia bruta excretada pela urina e MSI é a matéria seca ingerida. As variáveis utilizadas para avaliar a qualidade dos dejetos foram os teores de umidade, nitrogênio e fósforo nas fezes.

No experimento de desempenho, procedeuse ao arraçoamento duas vezes ao dia, às 7:00 e às 17:00 horas, fornecendo-se sempre quantidades suficientes para saciar os animais, tomando-se por base as sobras nos comedouros. A ração para baia era pesada em recipientes plásticos, adicionandose água, com posterior homogeneização, na proporção estabelecida para compor os tratamentos, para, então, ser servida aos animais. A limpeza das baias era realizada a cada dois dias e a limpeza dos comedouros a cada semana, com o auxílio de espátulas. Submeteram-se as sobras à perda de água em estufa de circulação forçada a 55 ${ }^{\circ} \mathrm{C}$ durante 72 horas, para se precisar a quantidade de ração seca não consumida pelos animais.

As variáveis estudadas foram o consumo de ração, o ganho de peso e a conversão alimentar. O término do experimento ocorreu quando a média do peso dos animais de cada unidade experimental atingiu a faixa dos $100 \mathrm{~kg}$ de peso vivo, ocasião em que os animais foram abatidos para avaliação de carcaça, seguindo metodologia descrita por BRIDI \& SILVA (2006).

Os resultados de digestibilidade, de ingestão de água de bebida, de qualidade dos dejetos e de desempenho foram submetidos à análise de variância. Para a comparação de médias, foi utilizado o teste Student Newman Keuls (SNK) a 5\% de probabilidade. Toda a análise estatística foi realizada no programa estatístico SAS (SAS, 2000).

\section{RESULTADOS E DISCUSSÃO}

Os respectivos valores de temperatura e umidade, mínimas e máximas, durante o ensaio de digestibilidade foram $22,3 \pm 0,6{ }^{\circ} \mathrm{C}$ e $31,1 \pm 1,1$ ${ }^{\circ} \mathrm{C}$, e $59,9 \pm 5,4 \%$ e $93,1 \pm 2,9 \%$; e durante o ensaio de desempenho foram, respectivamente, $22,1 \pm 0,8{ }^{\circ} \mathrm{C}$ e $30,6 \pm 0,7{ }^{\circ} \mathrm{C}$, e $58,0 \pm 3,3 \%$ e $93,2 \pm 3,1 \%$.

Durante a análise das médias dos coeficientes de digestibilidade dos nutrientes e da energia (Tabela 2), verificou-se que relatos a respeito da digestibilidade de nutrientes de dietas líquidas para suínos em terminação ainda são escassos na literatura. $\mathrm{O}$ fato de não ter havido efeito da adição de água nas rações para os animais, nesta fase, sobre a digestibilidade de nutrientes e da energia pode estar relacionado à dieta servida, que é do tipo não fermentada. Utilizando-se dietas com adição de água em rações não fermentadas para leitões com peso médio aproximado de 19,0 kg, SILVA et al. (2011) verificaram efeito apenas para o coeficiente de metabolização da proteína bruta, melhorado para dietas úmidas (relação água: ração 1:1) e liquidas (relação água: ração 2:1) comparado a rações secas.

CANIBE \& JENSEN (2003) distinguiram alimentação líquida fermentada e não fermentada: a não fermentada é a ração misturada com ingredientes líquidos, imediatamente antes do fornecimento para o animal, e a fermentada é a mistura de alimento seco com líquido, armazenada em ambiente controlado por determinado período antes do fornecimento para o animal. De acordo com LAWLOR et al. (2002), o efeito da fermentação leve da dieta é benéfico ao animal, por promover o equilíbrio entre o $\mathrm{pH}$ da dieta e do ambiente intestinal, em função dos altos níveis de bactérias lácticas, leveduras e ácido láctico produzidos. Como no ensaio em questão as dietas experimentais são do tipo não fermentada, elas não afetaram a ação de enzimas pancreáticas e intestinais, além de não terem diminuído a população de enterobactérias, o que minimizaria os efeitos de competição por nutrientes.

Constatou-se que, ao se avaliar as médias dos valores de nitrogênio retido da energia digestível e da energia metabolizável dos tratamentos em suínos em terminação (Tabela 2), apesar de não ter havido diferença $(\mathrm{P}>0,05)$ entre as dietas, os valores absolutos da ração seca são menores, quando comparados aos valores em que houve adição de água na ração. De acordo com os resultados, a adição de água em rações de suínos chega a reter $3,8 \mathrm{~g}$ a mais de nitrogênio por dia no organismo do animal, representando acréscimo diário de 10,8\%. Isso também ocorre para a energia digestível e metabolizável, pois houve acréscimo de até 100 e 116 kcal $/ \mathrm{kg}$, respectivamente, nas rações umedecidas quando comparadas com a ração farelada. SILVA et al. (2011) verificaram efeitos positivos sobre a digestibilidade do nitrogenio para dietas com adição de água na relação 1:1 e 2:1 para leitões na fase inicial. 
Tabela 2 - Coeficientes de digestibilidade da matéria seca, proteína bruta, energia bruta, extrato etéreo, coeficiente de metabolizabilidade da energia bruta, coeficiente de digestibilidade do cálcio e do fósforo e nitrogênio retido, contendo diferentes níveis de água adicionados em rações para suínos em terminação

\begin{tabular}{|c|c|c|c|c|c|}
\hline \multirow[b]{2}{*}{ Variáveis ${ }^{1}$} & \multicolumn{3}{|c|}{ Tipo de dieta fornecida ${ }^{2}$} & \multirow[b]{2}{*}{$\mathrm{P}$} & \multirow[b]{2}{*}{$\mathrm{CV} \%$} \\
\hline & $\begin{array}{c}\text { Ração } \\
\text { seca }\end{array}$ & $\begin{array}{l}\text { Ração } \\
\text { úmida }\end{array}$ & $\begin{array}{l}\text { Ração } \\
\text { líquida }\end{array}$ & & \\
\hline Coeficiente de digestibilidade da matéria seca (\%) & 90,1 & 90,6 & 90,8 & 0,61 & 2,5 \\
\hline Coeficiente de digestibilidade da proteína bruta (\%) & 87,2 & 89,5 & 89,5 & 0,56 & 4,0 \\
\hline Nitrogênio retido (g/dia) & 31,2 & 35,0 & 33,1 & 0,34 & 10,0 \\
\hline Coeficiente de digestibilidade do extrato etéreo (\%) & 83,6 & 86,7 & 83,8 & 0,53 & 6,7 \\
\hline Coeficiente de digestibilidade do cálcio (\%) & 70,2 & 74,6 & 71,8 & 0,90 & 7,0 \\
\hline Coeficiente de digestibilidade do fósforo(\%) & 68,7 & 68,4 & 70,5 & 0,88 & 10,3 \\
\hline Coeficiente de digestibilidade da energia bruta (\%) & 88,5 & 90,6 & 88,9 & 0,38 & 2,6 \\
\hline Coeficiente de metabolizabilidade energia bruta $(\%)$ & 87,0 & 89,7 & 87,9 & 0,39 & 2,6 \\
\hline
\end{tabular}

${ }^{1}$ Base na matéria seca; ${ }^{2}$ tratamentos: ração seca, ração úmida = relação água:ração $1: 1$ e ração liquida = relação água:ração 2:1

Ao se avaliar as variáveis de desempenho de suínos, na fase de terminação, alimentados com diferentes conteúdos de água adicionados à ração (Tabela 3), não se constatou diferença significativa entre os tratamentos. Os resultados encontrados não estão de acordo com os relatados por NIVEN et al. (2006) a respeito de alimentação líquida para suíno na fase de terminação, com utilização de água extraída do milho por maceração como diluente (em torno de $2.293 \mathrm{~g}, 899 \mathrm{~g}$ e 2,55para consumo de ração, ganho de peso e conversão alimentar, respectivamente). Provavelmente, a água extraída do milho por maceração, por apresentar nutrientes, quando comparada com água pura, contribuiu para as diferenças encontradas em relação a este ensaio.

Notou-se redução da ingestão de água in natura de até $0,87 \mathrm{~kg}$, em animais que recebem dieta líquida, comparados com animais que consumiram ração seca (Tabela 3). Essa redução de $28 \%$, certamente, está relacionada ao fato de parte da exigência diária de água ser suprida pela água adicionada às dietas, levado o animal a ir menos vezes ao bebedouro, o que pode ser considerado vantajoso para o sistema de alimentação líquida. YANG et al. (1981) constataram redução no consumo de água quando dietas peletizadas foram oferecidas secas ou misturadas com água na relação duas partes de água e uma de ração. DYBKJÆER et al. (2006) enfatizaram que leitões apresentam estreita relação entre o consumo de água e de ração e que especialmente a composição da dieta e a temperatura ambiente alteram a quantidade de água ingerida.

Para umidade das fezes, excreção de fósforo e nitrogênio fecal (Tabela 3), não houve diferença $(\mathrm{P}>0,05)$ entre os tipos de dieta fornecidos.

Tabela 3 - Desempenho, água ingerida in natura, umidade das fezes, nitrogênio fecal, cálcio fecal e fósforo fecal em suínos na fase de terminação em função de rações contendo diferentes níveis de água adicionados em rações para suínos em terminação

\begin{tabular}{|c|c|c|c|c|c|}
\hline \multirow{2}{*}{ Variável } & \multicolumn{3}{|c|}{ Tipo de dieta fornecida $^{1}$} & \multirow{2}{*}{$P$} & \multirow{2}{*}{$\mathrm{CV} \%$} \\
\hline & Ração seca & Ração úmida & Ração líquida & & \\
\hline Consumo de ração (g / dia) & 3075 & 3052 & 3081 & 0,99 & 9,6 \\
\hline Ganho de peso (g/ dia) & 999 & 1067 & 1001 & 0,58 & 11,2 \\
\hline Conversão alimentar & 3,07 & 2,89 & 3,09 & 0,49 & 9,2 \\
\hline $\begin{array}{l}\text { Água ingerida in natura }(\mathrm{kg} / \mathrm{kg} \text { de matéria seca } \\
\text { ingerida) }\end{array}$ & $3,11^{\mathrm{a}}$ & $3,31^{\mathrm{a}}$ & $2,24^{\mathrm{b}}$ & 0,05 & 14,5 \\
\hline Umidade das fezes (\%) & 64,9 & 62,2 & 63,8 & 0,39 & 2,7 \\
\hline Fósforo fecal (g / dia) & 4,78 & 5,10 & 5,16 & 0,69 & 13,1 \\
\hline Nitrogênio fecal (g / dia) & 6,00 & 5,50 & 4,75 & 0,48 & 25,6 \\
\hline
\end{tabular}


Constatou-se, na ocasião do experimento, que, após a oferta de ração, os animais consumiam praticamente a totalidade do que foi oferecido num período inferior a trinta minutos. Isso provavelmente aumentou os movimentos peristálticos, acarretando alta taxa de passagem do alimento, o que pode ter contribuido para o melhor aproveitamento dos nutrientes das dietas umedecidas. A realização do arraçoamento imediatamente após a mistura da água à ração farelada pode ter influenciado os resultados encontrados.

Em granjas comerciais que utilizam o sistema automatizado de alimentação líquida para suínos, a frequência diária de arraçoamento, realizado em porções menores, é de até oito vezes, permitindo melhor aproveitamento dos nutrientes por parte dos animais. BROOKS et al. (2003) mencionaram problemas quanto ao uso do sistema de alimentação líquida, tais como a mecanização e automatização do sistema, dificuldade de compatibilizar a técnica da alimentação líquida com as reais necessidades nutricionais dos suínos e encontrar a diluição ideal, que depende dos ingredientes utilizados e da participação de cada um deles nas dietas, além da possibilidade da ocorrência de processos fermentativos.

Não houve diferença $(\mathrm{P}<0,05)$ para rendimento de carcaça, comprimento de carcaça e espessura de toucinho em função da água adicionada às dietas (Tabela 4), de modo que os valores para rendimento de carcaça estão em concordância com os relatados por NIVEN et al. (2006).

Tabela 4 - Rendimento de carcaça, comprimento de carcaça e espessura de toucinho de suínos na fase de terminação, alimentados com rações contendo diferentes níveis de água adicionados em rações para suínos em terminação

\begin{tabular}{lcccccc}
\hline \multirow{2}{*}{ Variável } & \multicolumn{3}{c}{ Tipo de dieta fornecida } & & \\
\cline { 2 - 4 } & $\begin{array}{c}\text { Ração } \\
\text { seca }\end{array}$ & $\begin{array}{c}\text { Ração } \\
\text { úmida }\end{array}$ & $\begin{array}{c}\text { Ração } \\
\text { líquida }\end{array}$ & P & CV \% \\
\hline Rendimento de Carcaça (\%) & 77,45 & 75,44 & 75,65 & 0,37 & 3,47 \\
Comprimento de carcaça (cm) & 97,67 & 93,00 & 96,67 & 0,20 & 3,79 \\
Espessura de toucinho P1 (cm) & 4,25 & 4,21 & 3,78 & 0,26 & 12,88 \\
Espessura de toucinho P2 (cm) & 2,59 & 2,93 & 2,31 & 0,36 & 27,72 \\
Espessura de toucinho P3 (cm) & 2,58 & 2,50 & 2,20 & 0,68 & 32,35 \\
Espessura de toucinho médio $(\mathrm{cm})$ & 3,14 & 3,21 & 2,76 & 0,38 & 18,88 \\
\hline
\end{tabular}

${ }^{1}$ tratamentos: ração seca, ração úmida = relação água:ração 1:1 e ração liquida = relação água:ração 2:1

\section{CONCLUSÕES}

A adição de água em rações de suínos na fase de terminação não influencia a digestibilidade aparente dos nutrientes da dieta, no desempenho dos animas, quando o arraçoamento é realizado duas vezes ao dia nem na a composição da carcaça. Além disso, diminui a ingestão de água in natura, levando a menor desperdício quando os animais vão ao bebedouro, podendo refletir, de forma positiva, no volume e no poder poluente dos dejetos.

\section{REFERÊNCIAS}

BEAL, J.D.; NIVEN, S.J.; CAMPBELL, A.; BROOKS, P.H. The effect of temperature on the growth and persistence of Salmonella in fermented liquid pig feed. International Journal of Food Microbiology, v. 79, n. 1-2, p. 99-104, 2002.
BERTOL, T. M.; BRITO, B. G. Efeito do óxido de zinco $\mathrm{x}$ sulfato de cobre com ou sem restrição alimentar, sobre o desempenho e ocorrência de diarréia em leitões. Revista Brasileira de Zootecnia, n. 2, v. 24, p. 279-288, 1995.

BRIDI, A.M.; SILVA, C.A. Métodos de avaliação da carcaça e da carne suína. Londrina: Midiograf, 2006.

BROOKS, P.H.; BEAL, J.D.; NIVEN, S. Liquid feeding of pigs. I. Potential for reducing environmental impact and for improving productivity. Animal Science Papers and Reports, v. 21, suppl., p. 1-7, 2003.

C. PLUMED-FERRER, C.; VON WRIGHT, A, Fermented pig liquid feed: nutritional, safety and regulatory aspects. Journal of Applied Microbiology, v.106, p. 351-368, 2009.

CANIBE, N.; JENSEN, B. B. Fermented liquid feedMicrobial and nutritional aspects and impact on enteric diseases in pigs. Animal Feed Science and Technology, v. 173, p.17-40, 2012. 
CANIBE, N.; JENSEN, B.B. Fermented and nonfermented liquid feed to growing pigs: Effect on aspects of gastrointestinal ecology and growth performance. Journal of Animal Science, v. 81, p. 20192031, 2003.

DUNG, N.N.X; MANH, L.H., OGLE, B. Effects of the Duration of Liquid Feeding on Performance and Nutrient Digestibility in Weaned Pigs. Livestock Research for Rural Development (online) v. 17, n.9, 2005. Disponivel em http://www.lrrd.org/lrrd17/9/xdun17102.htm. Acesso em 01 out 2012.

DYBKJÆR, L.; JACOBSEN, A. P; TØGERSEN, F. A.; POULSEN, H. D. Eating and drinking activity of newly weaned piglets: Effects of individual characteristics, social mixing, and addition of extra zinc to the feed. Journal of Animal Science, v. 84, n. 3, p.702-711, 2006.

FARZAN, A.; FRIENDSHIP, R.M.; DEWEY, C.E.; WARRINER, K.; POPPE, C.; KLOTINS, K. Prevalence of Salmonella spp. on Canadian pig farms using liquid or dry-feeding. Preventive Veterinary Medicine, v. 73, n.3, p. 241-254, 2006.

HAN, Y.K., THACKER, P. A.; YANG, J.S. Effects of the Duration of Liquid Feeding on Performance and Nutrient Digestibility in Weaned Pigs. Asian-Australasian Journal of Animal Science, v. 19, n.3, p.396-401, 2006.

JENSEN, B.B.; MIKKELSEN, L.L. Feeding liquid diets to pigs. In: GARNSWORTHY, P.C.; WISEMAN, J. Recent advances in animal nutrition. Nottingham: Univ. Press Nottingham, U.K., 1998, p. 107-126.

LAWLOR, P. G.; LYNCH, P.B.; GARDINER, G.E., CAFFREY, P.J.; O'DOHERTY, J.V. Effect of liquid feeding weaned pigs on growth performance to harvest. Journal of Animal Science, v. 80, p. 1725-1735, 2002.
SMET, S., DIERICK, N.A. Fermented liquid feed for pigs: a review Archives of Animal Nutrition, v. 64, n. 6, p. 437-466, 2010.

NIVEN, S.J.; ZHU, C.; COLUMBUS, D., LANGE, C.F.M. Chemical composition and phosphorus release of corn steep water during phytase steeping. Journal of Animal Science, v. 84, p.429, 2006.

PEDERSEN, C. STEIN, H.H. Effects of liquid and fermented liquid feeding on energy, dry matter, protein and phosphorus digestibility by growing pigs. Livestock Science, v.134, p.59-61, 2010.

PEKAS, J.C. Versatible swine laboratory apparatus for physiologic and metabolic studies. Journal of Animal Science, v. 27, n. 5, p. 1303-1309, 1968.

ROSTAGNO, H.S.; ALBINO, L.F.T..; DONZELE, J.L.; GOMES, P.C.; OLIVEIRA, R.F.; LOPES, D.C.; FERREIRA, A.S.;BARRETO, S.L.T. Tabelas brasileiras para aves e suínos: composição de alimentos e exigências nutricionais. Viçosa: UFV - DZO, 2005. 186 p.

SAS INSTITUTE. SAS user's guide: statistical analysis system, Release 8.0. Cary, NC, 2000. 544 p.

SILVA, D.J., QUEIROZ, A.C. Análise de alimentos: métodos químicos e biológicos. 3. ed.Viçosa: MG: Universidade Federal de Viçosa, 2002. 165 p.

SILVA, J.L.; LOPES, E.L.; NUNES, R.C.; FARIAS, L.A.; MASCARENHAS, A.G.; ROCHA, L.O.; Rações com diferentes níveis de inclusão de água para suínos na fase de creche Ciência Animal Brasileira, v.12, n.4, p.610 - 616, 2011

YANG, T.S.; HOWARD, B.; MACFARLANE W.V. Effects of food on drinking behaviour of growing pigs. Applied Animal Ethology, v. 7, n.3, p. 259-270, 1981.

MISSOTTEN, J.A.M.; MICHIELS, J.; OVYN, A; DE 